\title{
Music and language processing share behavioral and cerebral features
}

\author{
Clara E. James* \\ Faculty of Psychology and Educational Sciences, University of Geneva, Geneva Neuroscience Center, Geneva, Switzerland \\ *Correspondence: clara.james@unige.ch
}

\section{A commentary on}

Musical expertise and statistical learning of musical and linguistic structures

by Schön, D., and François, C. (2011). Front. Psychology 2:167. doi: 10.3389/ fpsyg.2011.00167

Both language and music consist of discrete elements organized in embedded hierarchical structures. Schön and François nicely expose in this review that musical expertise facilitates learning of both linguistic and musical structures. At the behavioral level, the musicians did not outperform the nonmusicians. However, ERP analyses showed that acquisition of boundary perception (segmentation) between units improved with musical training. The experimental strategy typically used to investigate segmentation relies in a learning phaseon passive exposition to artificially constructed linguistic and musical material (cf. Figure 1). The authors plausibly argue, also based on a solid literature in this field, that such perceptual learning partially relies on statistics. The probability that a certain element is followed by another is different between and within units (words or tone sequences). In the test phase, participants should discriminate units from non-units. Statistical learning is by no means restricted to the auditory domain.

Why would musical expertise facilitate such learning in language? Musical and linguistic syntactical capacities seem correlated (Jentschke et al., 2008; Jentschke and Koelsch, 2009, also see the cited sources by Schön and François, p. 5). Moreover, brain substrates for language and music production and perception partially neighbor or overlap each other, although hemispheric dominances for music and language manifest (Zatorre, 2001; Koelsch et al., 2002; Brown et al., 2006). Schön and François observed similar ERP responses to linguistic and musical test-items (cf. Figure 4).
Shared cerebral networks and behavioral features involved in processing of complex sound suggest common roots. As already suggested by Darwin in his book "The Descent of Man and Selection in Relation to Sex," a precursor or "proto language" may have preceded the emergence of separated musical and linguistic human capacities, explaining the observed brain and behavior commonalities. Vocal learning capacities possibly contributed to the "survival of the fittest." We share akin vocal learning capacities with other higher order vertebrates (birds, whales, etc.), as shown in recent comparative research (Huron, 2001; Hauser and McDermott, 2003). More precisely, not vocal discrimination as such, but learning of vocal discrimination seems innate.

Now learning is synonymous with plasticity. We can become experts in very different domains, and behavior and brain adapt accordingly, comprising brain adaptations on the functional and the structural level (Maguire et al., 2000; Pascual-Leone, 2001; Brecht and Schmitz, 2008; James et al., 2008; Oechslin et al., 2009; Schlaug et al., 2009). In this context it is not surprising, as the authors also state, that experts in the musical domain show increased learning capacities for segmentation in both music and language. I would argue that trained musicians segment more efficiently not because their statistical learning is better, but because their discrimination and memory of complex sound is better, therefore allowing improved statistical learning as compared to non-musicians, also in a nonmusical domain such as language.

In conclusion, joint examination of music and language constitutes a powerful means to gain further insight into the processing of highly structured complex sounds in language and music, and their shared behavioral and cerebral features. Schön and François provide us with compelling examples of such research.

\section{REFERENCES}

Brecht, M., and Schmitz, D. (2008). Neuroscience. Rules of plasticity. Science 319, 39-40.

Brown, S., Martinez, M. J., and Parsons, L. M. (2006). Music and language side by side in the brain: a PET study of the generation of melodies and sentences. Eur. J. Neurosci. 23, 2791-2803.

Hauser, M. D., and McDermott, J. (2003). The evolution of the music faculty: a comparative perspective. Nat. Neurosci. 6, 663-668.

Huron, D. (2001). Is music an evolutionary adaptation? Ann. N. Y. Acad. Sci. 930, 43-61.

James, C. E., Britz, J., Vuilleumier, P., Hauert, C. A., and Michel,C.M. (2008). Early neuronal responses in right limbic structures mediate harmony incongruity processing in musical experts. Neuroimage 42, 1597-1608.

Jentschke, S., and Koelsch, S. (2009). Musical training modulates the development of syntax processing in children. Neuroimage 47, 735-744.

Jentschke, S., Koelsch, S., Sallat, S., and Friederici, A. D. (2008). Children with specific language impairment also show impairment of music-syntactic processing. J. Cogn. Neurosci. 20, 1940-1951.

Koelsch, S., Gunter, T. C., v Cramon, D. Y., Zysset, S., Lohmann, G., and Friederici, A. D. (2002). Bach speaks: a cortical "language-network" serves the processing of music. Neuroimage 17, 956-966.

Maguire, E. A., Gadian, D. G., Johnsrude, I. S., Good, C. D., Ashburner, J., Frackowiak, R. S., and Frith, C. D. (2000). Navigation-related structural change in the hippocampi of taxi drivers. Proc. Natl. Acad. Sci. U.S.A. 97, 4398-4403.

Oechslin, M. S., Imfeld, A., Loenneker, T., Meyer, M., and Jancke, L. (2009). The plasticity of the superior longitudinal fasciculus as a function of musical expertise: a diffusion tensor imaging study. Front. Hum. Neurosci. 3:76. doi: 10.3389/neuro.09.076.2009

Pascual-Leone, A. (2001). The brain that plays music and is changed by it. Ann. N. Y. Acad. Sci. 930, 315-329.

Schlaug, G., Forgeard, M., Zhu, L., Norton, A., and Winner, E. (2009). Training-induced neuroplasticity in young children. Ann. N. Y.Acad. Sci. 1169, 205-208. Zatorre, R. J. (2001). Neural specializations for tonal processing. Ann. N. Y. Acad. Sci. 930, 193-210.

Received: 10 February 2012; accepted: 10 February 2012; published online: 28 February 2012.

Citation: James CE (2012) Music and language processing share behavioral and cerebral features. Front. Psychology 3:52. doi: 10.3389/fpsyg.2012.00052

This article was submitted to Frontiers in Auditory Cognitive Neuroscience, a specialty of Frontiers in Psychology. Copyright $(2012$ James. This is an open-access article distributed under the terms of the Creative Commons Attribution Non Commercial License, which permits non-commercial use, distribution, and reproduction in other forums, provided the original authors and source are credited. 